attitudes inhibit the creative enterprise. Psychotherapists who work with creative people know this.

Additionally, I suspect that Dr Brooks may himself have committed the crime of which he accuses Macdiarmid. He suggests in his letter that Macdiarmid fails to take note of the proportion of the book given over to Janet, and its emphasis on the importance of the work that came before Freud and influenced his thinking. For me this came over clearly in the review.

I liked Macdiarmid as a writer. He showed respect for an important and scholarly book. In particular I liked his elegant and witty 'attack-from-within' on some of the more pretentious aspects of the psychotherapeutic establishment. On reading Macdiarmid I return with renewed appreciation to Ellenberger. Surely this was an excellent review!

Ealing Hospital

C. A. CoghlaN

Uxbridge Road

Southall

Middlesex $U B 13 E V$

\section{ROC analysis}

SIR: I hesitate to take issue with Snaith \& Owens' (Journal May 1990, 156, 744-745) recommendations about presenting the results of a relative (or receiver) operating characteristic (ROC) analysis. ROC analysis examines the ability of a screening instrument to discriminate cases and non-cases across the whole spectrum of morbidity by plotting sensitivity against false positive rate for all possible cut-off points. However, there are good reasons for displaying a smoothed ROC curve rather than "a series of straight lines joining the points" as they suggest.

Unless the sample size is very large in relation to the number of scoring categories, the selection of a cut-off point from the actual as opposed to estimated data can be very misleading. Random bunching of response scores can result in apparently excellent results (in terms of sensitivity, specificity and overall misclassification rate) with a chosen cut-off point, whereas a slight alteration in the cut-off produces a much poorer result.

The best way to avoid giving a false impression is to show the smoothed ROC curve with $95 \%$ confidence intervals on either side. A convenient computer program (ROCFIT) is available which calculates the maximum-likelihood fitted ROC curve and other parameters (Metz et al, 1984).

The optimal cut-off point (that is, the best tradeoff between sensitivity and specificity) is at the point on the ROC curve which is the greatest perpendicular distance from the diagonal. Of course, any cut-off point may be chosen for a particular purpose: the smoothed ROC curve will give a maximumlikelihood estimate of the resulting sensitivity and specificity.

Department of Psychiatry

DAVID B. MUMFORD

University of Leeds

15 Hyde Terrace

Leeds LS2 9LT

\section{Reference}

Metz, C. E., Wang, P-L. \& Kronman, H. B. (1984) rochit Chicago: Department of Radiology and the Franklin McLean Memorial Research Institute, University of Chicago.

\section{The Lomax affair}

SIR: I read Harding's reappraisal of Lomax's contribution with great interest (Journal, February 1990, 156, 180-187). However, lest the impression be gained that asylums were places of brutality and inhumanity in general, it should be pointed that Lomax described conditions as he found them between 1917 and 1919-a period when conditions were highly unusual. Not only had many younger medical staff been called up, leaving men past retirement age to manage alone, but many attendants too had gone to war, leaving the asylums grossly under-staffed. Nor was that all; some asylums had been taken over for war casualties and thus other asylums (presumably including Bracebridge and Prestwich) became grossly overcrowded.

There were also severe shortages of food - a matter beyond the control of the asylum managers. In the Burntwood asylum, for instance, the meat allowance had been reduced from $1 \mathrm{~kg}$ per head weekly in 1916 to $0.64 \mathrm{~kg}$ in 1918 ; heating also was almost certainly inadequate as the cost of coal escalated. During 1914 there had been 108 deaths within the asylum, but in 1918 there were 256, and these figures cannot be explained by an outbreak of influenza which accounted for only a few deaths. The strong implication is that malnutrition occurred. Nor was the Burntwood asylum unique: in the Worcestershire asylum there were 134 deaths during the final quarter of 1917 , whereas during the whole of 1916 there had been 148 deaths.

Thus, if Lomax found “. . . poor nutrition . . . and a high death rate ...", then this finding is in harmony with what was happening elsewhere and is a reflection of the harsh conditions which prevailed at that time. Of course, there can be no excuse for brutality and perhaps Harding's comment that "Prestwich 